\title{
The Definitions of Sharing Economy: A Systematic Literature Review
}

\author{
GEORGINA GÖRÖG \\ Kaposvár University, Hungary \\ georgina.gorog@gmail.com
}

\begin{abstract}
Nowadays sharing economy phenomenon is a popular topic among companies and academic researchers too. People share their intangible assets and underutilized tangible assets for money or for free with the help of the Internet which results in a new business model and creates a unique research area. The most popular expressions for this phenomenon are sharing economy and collaborative consumption; however, there are much more other definitions which refer to this. In order to new companies can enter and stabilize position on the market, they tend to use 'sharing economy' for their operation regardless of their business model which may mislead the customers. There is no clear agreement which is the only one definition that describes the sharing economy in the best way; there is a gap in the literature. For this reason, the purpose of this paper is to analyse the various expressions and make a clear difference between them. To achieve this goal, a systematic literature review has been carried out. According to the literature, 14 core definitions can be identified closely to sharing economy which means more or less the same; but not exactly the same. The result of this study shows how these are connected to each other and how their borders can be defined.
\end{abstract}

Key words: sharing economy, definition, categorization, literature review https://doi.org/10.26493/1854-4231.13.175-189

\section{Introduction}

Consumption patterns have been changed since the sharing economy phenomena started to become more popular (Botsman and Rogers 2010) and reached the traditional industries such as tourism, hospitality, transportation, education, job market and so on. It is a fast-growing concept its pros and cons that created new opportunities and business models. According to Davis (2016), the paradigm shift caused by technology could be bigger than the industrial revolution so he points out that managers should be prepared for the changes and adapt to the new circumstances.

Sharing is not a new phenomenon in our society; the new forms of sharing have appeared in recent years (Schor and Fitzmaurice 
2015) and this is the reason why it seems to be a new and disruptive model. While money means the ownership of a product in the neoclassic market, sharing economy structure demonstrates the benefit of capturing value with short-term access-rights to a product or service (Daunoriené et al. 2015). This represents an innovation that is able to reallocate money across the value chain, in particular away from intermediaries and towards consumers (Schor and Fitzmaurice 2015).

Apart from having economic consequences, the sharing economy is claimed to have positive environmental and social effects. It reduces the environmental impact, results in an efficient utilization of physical assets and facilitates new social contacts (Botsman and Rogers 2010). The collaboration can create innovation, jobs and community (Krueger 2012); the sharing could bring people together and stimulate social cohesion in neighbourhoods (Agyeman and McLaren 2015). On the other hand, the lack of its legal regulation, consumer protection and working conditions (Malhotra and Van Alstyne 2014) proves that this is a controversial concept. Schor (2014) highlights its overrated environmental gains and the erosion of workers' rights. She argues the unfair competition between platforms and regular companies and remarks the tendency towards monopoly (Schor 2014).

Based on the online ethnography method and journal article collection, Martin (2016) classified six possible outcomes regarding sharing economy; ranging 'from a potential pathway to sustainability to a nightmarish form of neoliberalism' (Martin 2016 p. 149): first category (1) is an economic opportunity. The second group (2) is a more sustainable form of consumption, (3) is a pathway to a decentralised, equitable and sustainable economy, (4) creating unregulated marketplaces, (5) reinforcing the neoliberal paradigm and (6) an incoherent field of innovation. His aim was to identify the different scenarios regarding the future of sharing economy. He assumes if the sharing economy follows its current way; it is unlikely that it drives towards to sustainability.

Although sharing economy phenomenon is clear, it has no bright understanding between academics and practitioners too. Plenty of various definitions exist in the literature; however, most of them are different from each other. Since sharing economy is a popular buzzword nowadays, companies tend to emphasize that they have 'sharing economy business model' so that they can reach more people on the market. Having this lack of understanding, the main goal of this article determines the numerous concepts related to sharing econ- 
omy and make difference between them, furthermore classify their meanings. The chosen method is the systematic literature review; because with help of this structured methodology, the definitions can be described and their similarities and differences can be identified.

\section{Main Drivers of Sharing Economy}

Sharing is not a new phenomenon; people shared their goods with their family, friends and neighbours since they started to live in communities (Belk 2014b; Schor 2014). With the development of the Internet, several new business models and new types of companies were born (Schmuck 2015) that made the commerce much easier. As a result, users can borrow goods from strangers and lend to them, because the Internet has decreased the transaction costs extremely between participants (Frenken and Schor 2017).

In this model, the new innovation is that the majority of business transactions are cheaper than a similar transaction among the participants who are buying goods and services on the 'classic' economic field (Möhlmann 2015). Additionally, the power of the sharing economy is enhanced by the increasing scarcity of resources, urbanisation, and social and demographic changes (Zilahy 2016).

Böcker and Meelen (2016) provide a comprehensive background regarding the sharing economy's environmental, societal and economic aspects. They state that the popularity of sharing economy started after the financial crisis of 2007-2008 because people experience financial difficulties since then, they would re-evaluate their consumption patterns and the value of the ownership. Individuals who lost their jobs needed to find new job opportunities and companies such as UBER offered an attractive alternative (Kathan, Matzler, and Veider 2016). According to Puschmann and Alt (2016), the most important drivers towards this economy are changing consumer behaviour (the tendency from ownership to access), social networks and electronic markets (transactions among peers) and mobile devices and electronic services ('app economy,' buying with the help of our electronic devices).

In terms of social sciences, three main areas can be identified in connection with the sharing economy: (1) sociological approach; it focuses on the changing role of individuals, the more conscious and responsible consumer behaviour and the growing altruistic mentality. (2) Economics approach; in this meaning, the sharing economy has a positive effect on innovation and stimulates the competition. (3) Management theories: it refers to the emergence of new business models and a new type of entrepreneurship and service provider ap-

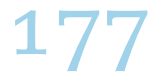


proach that may enhance the traditional industries (Codagnone and Martens 2016).

The biggest success factor of the sharing economy is the online reputation and feedback system where buyers and sellers can evaluate each other. Participants have risks in terms of trust and credibility; one of the most serious risk factors is the lemon problem that exists because buyers and sellers do not know each other, usually, they do not meet, therefore, there has asymmetric information about quality and value of product and service (Bae and Koo 2017). The online feedback and reputation system can enhance the trust between participants. This feature is not new, it existed earlier too; other wellknown e-business online portals such as eBay or Amazon used this earlier. Yet, this is one of the key success factors of all sharing economy platforms. Luca (2011) states that the user-generated online reviews have huge credibility in case of customers and this is an essential part of the decision making process. With the help of this system, the stranger sharing is less risky because of the use of ratings and reputation mechanism (Tadelis 2017).

\section{Research Methodology}

In this paper, the research is based on Prisma protocol method for systematic literature review (ter Huurne et al. 2017). The protocol consists of four stages (see http://prisma-statement.org):

$$
\text { identification } \mapsto \text { screening } \mapsto \text { eligibility } \mapsto \text { inclusion }
$$

In stage 1 the relevant studies were identified. We conducted a research on Google Scholar and Science Direct searching title/abstract/keyword. Since this is a relatively new research area, we also used a simple google research to identify and understand the definitions and related context. Furthermore, the snowball method also helped to find the relevant articles: we searched for authors who have at least three articles related to sharing economy (Belk 2010; Botsman and Rogers 2010; Frenken 2015; Hawlitschek et al. 2016; Martin 2015; Teubner 2014; Schor 2014) and it helped to name and classify the main trends and concepts.

During the investigation, we used keywords and focused on the interpretation of sharing economy and its related definitions. In stage 2 our aim was to find the definitions that are used interchangeably with sharing economy. We focused on papers and articles where definitions are mentioned so all research materials that did not contain an explanation of sharing economy or its related expressions have been excluded.

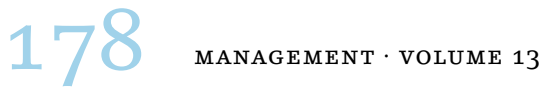




\section{Discussion and Results}

SHARING ECONOMY AND ITS RELATED DEFINITIONS

There are a misunderstanding and ambiguity in terms of sharing economy among academics and the public sector. This concept is popular nowadays and it is a new buzzword that entrepreneurs and companies prefer to use, regardless of their business model. It can be misleading; therefore the main purpose of this study is to identify the various definitions regarding sharing economy and to make clear how they are connected and what is the difference between them.

So far there is no the 'only one' commonly agreed definition for sharing economy (Oh and Moon 2016); Botsman (2013) says that 'the sharing economy lacks a shared definition' (p. 24). Hawlitschek et al. (2016) state that one reason for this lack is the rapid development of the field. In popular meaning and academic literature too, it is commonly used as an umbrella term for a broad spectrum of services, activities and businesses (Hamari, Sjöklint, and Ukkonen 2016).

According to Botsman (2015) and Rinne (2017), the most popular definitions regarding the sharing economy are collaborative economy, collaborative consumption, on-demand economy, on-demand services, gig economy, freelance economy, peer economy, access economy, crowd economy, digital economy and platform economy. Dredge and Gyimóthy (2015) examined the genealogy of the sharing economy and they found 17 terms related to this. They say that the conceptualization depends on its area of origin; such as human ecology, computer science, neoclassic microeconomics, anthropology, post-modern sociology, philosophy, politics or cultural theory. They found the following terms:

- Human Ecology

- Collaborative Consumption

- Access Economy

- Moral Economy

- Social Sharing

- Alternative Post-Capitalist Economies

- Collaborative Consumption v 2.0

- Collaborative Lifestyles

- The Mesh (aka the Sharing society)

- Circuits of Commerce

- Access-Based Consumption

- Peer Economy 
- Moral Economy (of Alternative Tourism)

- Sharing vs. Pseudo Sharing

- Connected Consumption

- Collaborative Commerce

- Sharing economy

- Hybrid Economy

Other notions and descriptions include anti-consumption (Albinsson and Perera, 2012), peer-to-peer markets (Fraiberger and Sundararajan 2015) and for-profit or non-profit sharing (Henten and Windekilde 2015).

These definitions are often being used interchangeably. There is an overlap between them but they might mean very different things that are important to understand. Online platforms where we can order a cleaning lady, massage or lunch from a restaurant are fundamentally different from platforms like Airbnb that is built on the sharing of the underused asset (Botsman 2015).

\section{INTERPRETATION OF DEFINITIONS}

Based on the listings earlier, there are more than 26 different terms related to sharing economy it means that there is a need to conceptualize them. In table 1 there is the 15 most popular definition based on Google search. These will be explained and expanded in the next part.

\section{Digital Economy}

The Internet has numerous positive consequences, one of them is that more and more businesses exist online. Nowadays it is difficult to imagine a company who does not have a webpage or email address. Digital economy means the economic activity with help of mobile technology and the internet of things (гот) that result from billions of everyday online connections among people, businesses, devices, machines, data, and processes (Cassar, Heath, and Micallef 2010). According to Rinne (2017), this expression refers to anything powered by digital technologies.

\section{Gig Economy}

Gig economy means the temporary, project-based and flexible jobs. Companies that hire independent contractors and freelancers instead of full-time employees part of this so-called gig economy (see https://www.investopedia.com/terms/g/gig-economy.asp). 
TABle 1 The 15 Most Popular Terms Related to Sharing Economy ('Sharing Economy' is also part of the research)

\begin{tabular}{lll}
\hline Rank & Definition & Number of results on Google \\
\hline 1 & Digital economy & $4,960,000$ results $(0.50 \mathrm{sec})$ \\
2 & Sharing economy & 3,860, ooo results $(0.37 \mathrm{sec})$ \\
3 & Gig economy & $2,190,000$ results $(0.40 \mathrm{sec})$ \\
4 & On-demand services & $2,040,000$ results $(0.36 \mathrm{sec})$ \\
5 & On-demand economy & 717,000 results $(0.35 \mathrm{sec})$ \\
6 & Platform economy & 434,000 results $(0.52 \mathrm{sec})$ \\
7 & Collaborative consumption & 418,000 results $(0.30 \mathrm{sec})$ \\
8 & Collaborative economy & 214,000 results $(0.33 \mathrm{sec})$ \\
9 & Product-Service System (Pss) & 160,000 results $(0.40 \mathrm{sec})$ \\
10 & Freelance economy & 59,000 results $(0.36 \mathrm{sec})$ \\
11 & Peer economy & 48,300 results $(0.43 \mathrm{sec})$ \\
12 & Access economy & 27,900 results $(0.33 \mathrm{sec})$ \\
13 & Second hand platform & 13,400 results $(0.27 \mathrm{sec})$ \\
14 & Crowd economy & 12,100 results $(0.34 \mathrm{sec})$ \\
15 & Second hand economy & 11,800 results $(0.32 \mathrm{sec})$ \\
\hline
\end{tabular}

On-Demand Services and On-Demand Economy

On-demand economy focuses on 'on-demand' needs, in other words, the immediate access-based goods and services. Online platforms, that provide this direct access to customers according to their needs, are part of the on-demand economy (Botsman 2015). Frenken et al. (2015) say that with the help of on-demand service platforms consumers can deliver personal services to each other.

Platform Economy

Similarly to the digital economy, companies are creating online structures that enable a wide range of human activities (KenneyZysman 2016).

\section{Business-to-Consumer 'Product-Service' Models or Product-Service Systems}

Product Service Systems (PSSS) or product-service models have a large literature and it refers to the new utilization concept (Baines et al. 2007) which means that the 'using' is becoming more important than 'owning.' In practice, companies rent out their good to customers for temporary use (Frenken et al. 2015) which can happen online and offline too. Pss refers to a shift toward less resource based consumption culture (Leismann et al. 2013), where consumers favour renting, bartering, and exchange (Tussyadiah and Pesonen 
2015). A good example is a firm from whom car can be rented for short term.

\section{Freelance Economy}

Similarly to the gig economy, freelance economy means the workforce participation and income generation by freelancers or independent workers (Rinne 2017).

\section{Peer Economy}

Peer to peer economy refers to the business between customer and customer without any intermediaries. They can buy and sell products and services from each other.

\section{Access Economy}

'Access economy' or 'access-based consumption' is one type of the economy that offers customers access to products or services when they want it (Gobble 2017) but not exactly the same; it helps to purchasers who could not afford to own or do not want to own a product but they need for it for short-term (Bardhi and Eckhardt 2012). This form of purchasing may help to protect our environment with less use of products and natural resources (Leismann et al. 2013).

\section{Second Hand Platforms}

On second-hand platforms, customers can sell or give away their used goods to other customers (Frenken et al. 2015). The most typical second-hand platform is eBay but the second-hand clothes shops are also quite popular.

\section{Crowd Economy}

Crowd economy focuses on the 'crowd' and refers to crowdsourcing and crowdfunding (Rinne 2017). According to Sundararajan (2016, 35), the 'crowd-based capitalism is the way in which platforms like Uber and Airbnb draw on the resources of the crowd to serve the needs of the crowd, taking their cut along the way.'

\section{Collaborative Consumption}

Nowadays one of the most popular expressions is collaborative consumption and based on the literature we can conclude that people substitute it for sharing economy and this exists back and forth. Lin and Huang (2013) say that this involves sharing information, investment fund and collaborative production (Lorena, Hernandez-Ortega

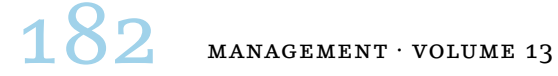


TABLE 2 Definitions of Collaborative Consumption

\begin{tabular}{ll}
\hline Author & Definition \\
\hline $\begin{array}{l}\text { Belk (2014a, } \\
\text { 1597) }\end{array}$ & $\begin{array}{l}\text { Collaborative consumption as 'people coordinating the acquisition } \\
\text { and distribution of a resource for a fee or other compensation.' }\end{array}$ \\
\hline $\begin{array}{l}\text { Botsman } \\
(2015,18)\end{array}$ & $\begin{array}{l}\text { The reinvention of traditional market behaviours-renting, lend- } \\
\text { ing, swapping, sharing, bartering, gifting-through technology, tak- } \\
\text { ing place in ways and on a scale not possible before the internet. }\end{array}$ \\
\hline $\begin{array}{l}\text { Hamari, Sjök- } \\
\text { lint, and Ukko- }\end{array}$ & $\begin{array}{l}\text { Collaborative consumption has also been defined as 'a peer-to- } \\
\text { nen (2015, }\end{array}$ \\
$\begin{array}{l}\text { goods and sed activity of obtaining, giving, or sharing the access to } \\
\text { services.' }\end{array}$ \\
$\begin{array}{ll}\text { Tussyadiah } & \text { Collaborative consumption can be traced back to the well- } \\
\text { and Pesonen } & \text { established form of resource exchanges in our socioeconomic sys- } \\
\text { (2015, 156) } & \text { tem. }\end{array}$ \\
\hline
\end{tabular}

Blanca, and Jimenez-Martinez 2014). Other researches point out different aspects of this term. According to Rinne (2017), the phrase indicates collaborative forms of consumption, production, finance and learning, furthermore she says that collaborative consumption is closest to the orthodox sharing economy definition. Belk (2014a) refers to an early definition worded by Felson and Speath (1978); they said that joint activities involving consumption (e.g., drinking beer with friends), but not necessarily captured the sharing aspects of the consumption (i.e., distribution of resources to others for their use) was meant to be an early type of collaborative consumption.

Collaborative consumption 'highlights the importance of market mediation (i.e. systems of exchange) and the power of social network effects (i.e. peer-to-peer sharing enabled by social technologies)' (Cusumano 2015, 34). We listed more definitions in table 2 to make the expression of collaborative consumption more sophisticated.

\section{Sharing Economy}

The well-known expression, 'sharing economy' refers to the sharing activity of underutilized assets with the help of Iт-based technology. Researchers understand this expression in various ways pointed out its numerous aspects (table 3). According to Belk (2014a) sharing has a too broad definition (for instance sharing, bartering, lending, trading, gifting, swapping, etc.) that contributes to the misinterpretation of the basic idea.

There are similarities between definitions' of sharing economy and descriptions' of collaborative consumption. Based on the literature - in a strict sense - sharing economy is narrower than collabo- 
TABLE 3 Definitions of Sharing Economy

\begin{tabular}{ll}
\hline Author & Definition \\
\hline $\begin{array}{l}\text { Belk (2014a, } \\
\text { 1597) }\end{array}$ & $\begin{array}{l}\text { He distinguishes 'true' and 'pseudo-sharing.' 'True sharing' as en- } \\
\text { tailing temporary access rather than ownership, no fees or com- } \\
\text { pensation, and use of digital platforms. The majority of commer- } \\
\text { cial platforms included in 'sharing economy' do not belong there. }\end{array}$ \\
\hline $\begin{array}{l}\text { Frenken et al. } \\
\text { (2015, 245) }\end{array}$ & $\begin{array}{l}\text { The 'sharing economy' means when 'consumers (or firms) grant- } \\
\text { ing each other temporary access to their under-utilized physical } \\
\text { assets (idle capacity), possibly for money.' }\end{array}$ \\
\hline $\begin{array}{l}\text { ofcD (2015, } \\
\text { 53) }\end{array}$ & $\begin{array}{l}\text { Online platforms specialised in 'matching demand and supply in } \\
\text { specific markets, enabling peer-to-peer (P2P) sales and rentals.' }\end{array}$ \\
& $\begin{array}{l}\text { It identifies three types: (a) P2P selling (b) P2P sharing; and (c) } \\
\text { crowdsourcing. }\end{array}$ \\
\hline $\begin{array}{l}\text { Pricewater- } \\
\text { houseCoopers } \\
\text { (2015, 3) }\end{array}$ & $\begin{array}{l}\text { The 'sharing economy uses digital platforms to allow customers to } \\
\text { hassets.' }\end{array}$ \\
\hline Rinne (2017) & $\begin{array}{l}\text { The focus is on the sharing of underutilised assets, monetised or } \\
\text { not, in ways that improve efficiency, sustainability and community. }\end{array}$ \\
\hline
\end{tabular}

rative consumption since its re-use of underutilised assets. Another important element is that it is for free not for financial compensation.

\section{Conclusion}

We conducted a review of the academic and grey literature (conference paper, articles on the internet) with the aim of investigating and analysing the sharing economy concept and its related definitions.

The most popular research areas regarding sharing economy are motivations to participate, trust is sharing economy, e-business and online feedback system and its unregulated market circumstances. Since this a relatively new research area, it is essential to understand the basic approach and its surroundings. It is important from academic and from the business perspective; because more and more companies are jeopardized by this new business model and they need to react to the changes. Managers should be up-to-date regarding the most recent technological changes and innovations so that they could protect their business and answer for the challenges.

We highlighted various definitions and phrases in relation to sharing economy and it can be concluded that there is no agreement on this area; what sharing economy means exactly. Figure 1 shows the connection among different definitions related to the sharing economy.

Based on the literature we can conclude that the closest definition 


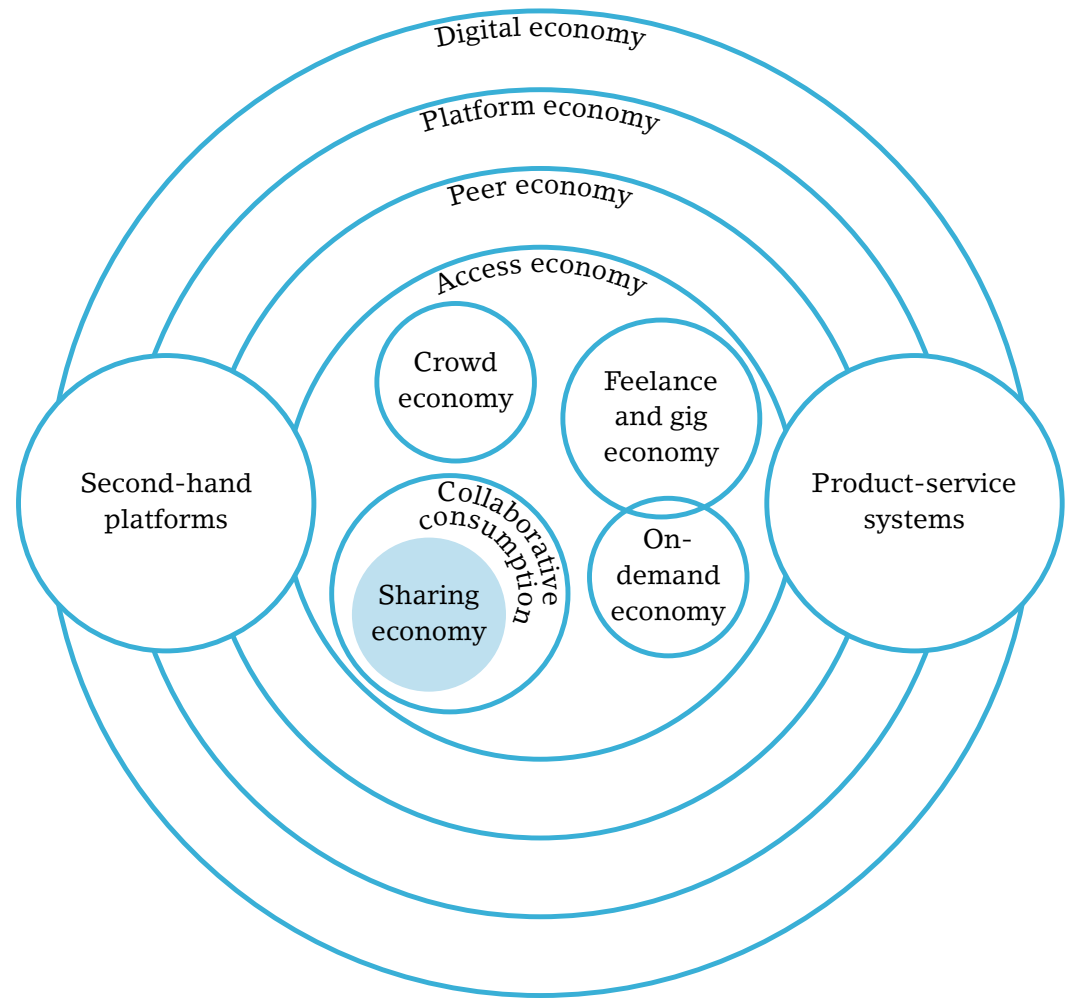

FIGURE 1 Definitions Regarding Sharing Economy and Their Positions Compared to Sharing Economy

is collaborative consumption; however it has an element of financial or other compensation, it means that in terms of narrow interpretation, sharing economy should not be about the financial settlement. In a strict sense - sharing economy refers to re-use of underutilised assets.

\section{Limitations and Opportunities for Further Research}

This study does have certain limitations. We focused on the definition and related concepts and disregarded the deep content or its positive and negative consequences. One of the biggest criticizes against the sharing economy is unclear and missing regulatory at local and national levels (its taxes, insurance, public safety, fair competition, employment situation are concerned by law) and this has not been covered by this paper. Also, its positive and negative consequences on communities have not been investigated, that are re- 
ally exciting research areas. There are authors who argue that the sharing economy can contribute to sustainable development and, as an alternative economic model, make a contribution to environmental sustainability (Heinrichs 2013; Cohen and Kietzmann 2014). As a matter of fact, these are other enormous research areas that we are planning to study separately.

Our aim was to understand the numerous terms related to sharing economy and make a difference between them. Considering that it is a relatively new and changing phenomenon it is not easy to identify its border. The number of literature is growing in this research field; therefore a broader research with the analysis of more articles would give a more sophisticated result.

The next step could be an empirical examination among firms that think that they operate on this field and ask them how they interpret the sharing economy.

\section{Acknowledgements}

This paper was supported by the New National Excellence Program of the Ministry of Human Capacities of Hungary (ÚNKP-17-3-I-KE-26).

\section{References}

Agyeman, J., and D. McLaren. 2015. Sharing Cities: A Case for Truly Smart and Sustainable Cities. Cambridge, мA: міт Press.

Albinsson, P. A., and Y. Perera. 2012. 'Alternative Marketplaces in the 21st Century: Building Community through Sharing Events.' Journal of Consumer Behaviour 11:303-15.

Baines, T. S., H. Lightfoot, E. Steve, A. Neely, R. Greenough, J. Peppard, R. Roy, E. Shehab, A. Braganza, A. Tiwari, J. Alcock, J. Angus, M. Bastl, A. Cousens, P. Irving, M. Johnson, J. Kingston, H. Lockett, V. Martinez, P. Michele, D. Tranfield, I. Walton, and H. Wilson. 2007. 'State-of-the-Art in Product-Service Systems.' Journal of Engineering Manufacture 221 (10): 1543-52.

Bardhi, F., and G. M. Eckhardt. 2012. 'Access-Based Consumption: The Case of Car Sharing.' Journal of Consumer Research 39:881-98.

Belk, R. W. 2010. 'Sharing.' Journal of Consumer Research 36 (5): 715-34.

- 2014a. 'Sharing versus Pseudo-Sharing in web 2.0' Anthropologist 18:7-23.

- 2014b. 'You Are What You Can Access: Sharing and Collaborative Consumption Online.' Journal of Business Research 67 (8): 1595600.

Botsman, R. 2013. 'The Sharing Economy Lacks A Shared Definition.' FastCompany, 21 November. https://www.fastcompany.com/3022028 /the-sharing-economy-lacks-a-shared-definition\#10 
2015. 'Defining The Sharing Economy: What Is Collaborative Consumption And What Isn't?' FastCompany, 27 May. https://www .fastcompany.com/3046119/defining-the-sharing-economy-what-is -collaborative-consumption-and-what-isnt

Botsman, R., and R. Rogers. 2010. What's Mine Is Yours. New York: Collins.

Cohen, B., and J. Kietzmann. 2014. 'Ride On! Mobility Business Models for the Sharing Economy.' Organization \& Environment 27:279-96.

Bae, J., and D.-M. Koo. 2018. 'Lemons Problem in Collaborative Consumption Platforms: Different Decision Heuristics Chosen by Consumers with Different Cognitive Styles.' Internet Research 28 (3): 746-766.

Böcker, L., and T. Meelen. 2016. 'Sharing for People, Planet or Profit? Analysing Motivations for Intended Sharing Economy Participation.' Environmental Innovation and Societal Transitions 23:28-39.

Cassar, C., D. Heath, and L. Micallef. 2010. 'What Is Digital Economy? Unicorns, Transformation and the Internet of Things.' https://www2 .deloitte.com/mt/en/pages/technology/articles/mt-what-is-digitaleconomy.html

Codagnone, C., and B. Martens. 2016. 'Scoping the Sharing Economy: Origins, Definitions, Impact and Regulatory Issues.' Institute for Prospective Technological Studies Digital Economy Working Paper 2016/o1. https://ec.europa.eu/jrc/sites/jrcsh/files/JRC100369.pdf

Cusumano, M. A. 2015. 'How Traditional Firms Must Compete in the Sharing Economy.' Communications of the ACM 58 (1): 32-34.

Daunorienè, A., A. Drakšaitè, V. Snieška, and G. Valodkienè. 2015. 'Evaluating Sustainability of Sharing Economy Business Models.' Procedia: Social and Behavioural Sciences 213:836-41.

Davis, G. F. 2016. 'Can an Economy Survive without Corporations? Technology and Robust Organizational Alternatives.' Academy of Management Perspectives 30 (2): 129-40.

Dredge, D., and S. Gyimóthy. 2015. 'The Collaborative Economy and Tourism: Critical Perspectives, Questionable Claims and Silenced Voices.' Tourism Recreation Researches 40:286-302.

Felson, M., and J. Speath. 1978. 'Community Structure and Collaborative Consumption.' American Behavioral Scientist 41:614-624.

Fraiberger, S. P., and A. Sundararajan. 2015. 'Peer-to-Peer Rental Markets in the Sharing Economy.' NET Institute Working Papers 15-19. http://www.netinst.org/Fraiberger_Sundararajan_15-19.pdf

Frenken, K., T. Meelen, M. Arets, and P. van de Glind 2015. 'Smarter Regulation for the Sharing Economy.' The Guardian, 20 May 20. https://www.theguardian.com/science/political-science/2015/may/ 20/smarter-regulation-for-the-sharing-economy

Frenken, K., and J. Schor. 2017. 'Putting the Sharing Economy into Perspective.' Environmental Innovation and Societal Transitions 23:3-10. 
Gobble, M. M. 2017. 'Defining the Sharing Economy.' Research Technology Management 60 (2): 59-61.

Hamari, J., M. Sjöklint, and A. Ukkonen. 2015. 'The Sharing Economy: Why People Participate in Collaborative Consumption.' Journal of the Association for Information Science and Technology 67 (9): 204759 .

Hawlitschek, F., T. Teubner, M. T. P. Adam, N. S. Borchers, M. Möhlmann, and C. Weinhardt. 2016. 'Trust in the Sharing Economy: An Experimental Framework.' Paper presented at the Thirty Seventh International Conference on Information Systems, Dublin, 11-14 December.

Heinrichs, H. 2013. 'Sharing Economy: A Potential New Pathway to Sustainability.' Gaia 22 (4): 228-31.

Henten, A., and I. M. Windekilde. 2015. 'Transaction Costs and the Sharing Economy.' Info 18 (1): 1-15.

Kathan, W., K. Matzler, and V. Veider. 2016. 'The Sharing Economy: Your Business Model's Friend or Foe?' Business Horizons 59 (6): 663-672.

Kenney, M., and J. Zysman. 2016. 'The Rise of the Platform Economy.' Issues in Science and Technology 32 (3). https://issues.org/the-riseof-the-platform-economy/

Krueger, N. 2012 ‘Bridging Town and Gown: Best Practice? An Essay on Growing the Local Entrepreneurial Ecosystem.' International Journal of Business and Globalisation 9 (4): 347-58.

Lin, F. R., and H. Y. Huang. 2013. 'Why People Share Knowledge in Virtual Communities? The Use of Yahoo! Kimo Knowledge+ as an Example.' Internet Research 23 (2): 133-59.

Leismann, K., M. Schmitt, H. Rohn, and C. Baedeker. 2013. 'Collaborative Consumption: Towards a Resource-Saving Consumption Culture.' Resources 2 (3): 184-203.

Lorena, B. A., B. Hernandez-Ortega Blanca, and J. Jimenez-Martinez. 2014. 'The Online Purchase as a Context for Co-Creating Experiences: Drivers of and Consequences for Customer Behaviour.' Internet Research 24 (3): 393-412.

Luca, M. 2011. 'Reviews, Reputation, and Revenue: The Case of Yelp .com.' Technical report, Harvard Business School, Boston.

Malhotra, A., and M. Van Alstyne, M. 2014. 'The Dark Side of the Sharing Economy ... and How to Lighten It.' Communications of the ACM 57 (11): $24-7$.

Martin, C. J. 2015. 'The Sharing Economy: A Pathway to Sustainability Or a New Nightmarish Form of Neoliberalism?' Ecological Economics 121:149-59.

Möhlmann, M. 2016. 'Digital Trust and Peer-to-Peer Collaborative Consumption Platforms: A Mediation Analysis.' https://doi.org/10.2139/ Ssrn. 2813367

OECD. 2015. Digital Economy Outlook 2015. Paris: oeCD. 
Oh, S., and J. Y. Moon. 2016. 'Calling for a Shared Understanding of the Sharing Economy.' Paper presented the 18th Annual International Conference on Electronic Commerce: E-Commerce in Smart Connected World, Suwon, 17-9 August.

Puschmann, T., and R. Alt. 2016. 'Sharing Economy' Business \& Information Systems Engineering: The International Journal of Wirtschaftsinformatik 58 (1): 93-99.

PricewaterhouseCoopers. 2015. 'The Sharing Economy: Sizing the Revenue Opportunity.' http://www.pwc.co.uk/issues/megatrends/ collisions/sharingeconomy/the-sharing-economy-sizing-the -revenue-opportunity.html

Rinne, A. 2017. 'What Exactly is the Sharing Economy?' World Economic Forum, 13 December. https://www.weforum.org/agenda/2017/12/ when-is-sharing-not-really-sharing/

Schmuck, R. 2015. 'Online üzleti modellek.' Doctoral Thesis, University of Pécs, Pécs.

Schor, J., 2014. Debating the Sharing Economy. Great Transition Initiative, October. https://www.greattransition.org/publication/debating -the-sharing-economy

Schor, J. B., and C. Fitzmaurice. 2015. 'Collaborating and Connecting: The Emergence of a Sharing Economy.' In Handbook on Research on Sustainable Consumption, edited by L. Reisch and J. Thogersen, 410-25. Cheltenham: Edward Elgar.

Sundararajan, A. 2016. The Sharing Economy, The End of Employment and the Rise of Crowd Based Capitalism. Cambridge, мA: The міт Press.

Tadelis, S. 2017. 'Reputation and Feedback Systems in Online Platform Markets.' Annual Review of Economics 8:321-40

ter Huurne, M., A. Ronteltap, R. Corten, and V. Buskens. 2017. 'Antecedents of Trust in the Sharing Economy: A Systematic Review.' Journal of Consumer Behaviour 16 (6): 485-98.

Teubner, T. 2014. 'Thoughts on the Sharing Economy.' Paper presented at the 8th Multi Conference on Computer Science and Information Systems, Lisbon, 15-9 July.

Tussyadiah, I. P., and J. Pesonen. 2015. 'Impacts of Peer-to-Peer Accommodation Use on Travel Patterns.' Journal of Travel Research 55 (8): 1-19.

Zilahy, G. 2016. 'Sustainable Business Models: What Do Management Theories Say?' Vezetéstudomány 47 (10): 62-72. 